\title{
Simultaneous Quantitation of Organic Acids and Monosaccharides by High-Performance Liquid Chromatography
}

\author{
$\mathrm{Lu}$ Xin \\ Institute of Agricultural Processing \\ Henan Academy of Agricultural Sciences \\ Zhengzhou, China \\ xinlu1981@foxmail.com
}

Shoji Hagiwara

National Food Research Institute

National Agriculture and Food Research Organization,

Tsukuba,Japan

shoji@affrc.go.jp.

\section{Song Guohui}

Institute of Agricultural Processing

Henan Academy of Agricultural Sciences

Zhengzhou, China

sigehe@126.com

\author{
Huang Jinian \\ Institute of Agricultural Processing \\ Henan Academy of Agricultural Sciences \\ Zhengzhou, China \\ hjinian@sina.com
}

\author{
Hiroshi Nabetani \\ National Food Research Institute \\ National Agriculture and Food Research Organization, \\ Tsukuba,Japan \\ nabetani@affrc.go.jp. \\ Li Ruihong \\ Institute of Agricultural Processing \\ Henan Academy of Agricultural Sciences \\ Zhengzhou, China \\ liruihong@163.com
}

\begin{abstract}
Objective: a fast, simply, reliably and accurately high-performance liquid chromatography (HPLC) method for the simultaneous quantitation of commonly used organic acid and monosaccharides in food industry such as benzoic, malic, citric and quinic acid, fructose, glucose has been developed. Methods: In order to obtain a satisfactory separation in a short elution time, various HPLC operational factors like composition of mobile phase, column temperature and flow rate affecting analysis had been optimized. Results: The optimum determination conditions are as follows: for a CAPCELL PAK $\mathrm{NH}_{2}$ column, flow rate of $1 \mathrm{~mL} / \mathrm{min}, 75 \%$ acetonitrile (pH 2.25 adjusted by phosphoric acid) as mobile phase, column temperature of 35 ${ }^{\circ} \mathrm{C}$. Under these conditions, this method could achieve adequate separation within $18 \mathrm{~min}$ and show the excellent linearity $\left(R^{2}>0.999\right)$, high precision (R.S.D $\left.<5 \%\right)$ and good accuracy (The recovery closed to $100 \%$ ). Moreover, the procedure of this method is very sample, involves little sample preparation which just consists of dilution and filtration before injection, and the cost of this method is relative low compared with ion-exchange HPLC method. Conclusion: it is promising method to simultaneous quantitation of organic acids and monosaccharides in food industry.
\end{abstract}

Keywords-organic acid; monosaccharides; simultaneous quantitation; fruit; beverage

\section{INTRODUCTION}

Organic acids and monosaccharides are natural compounds in fruits and vegetables. Moreover, some organic acid and monosaccharides added in beverages are citric, malic acid as acidulants, benzoic acid as preservative, glucose and fructose as sweetener ${ }^{[1]}$. The data of the quality and quantity of sugars and organic acids, as well as the rations of the single saccharides to each other and the ratios of sugars to the acids proved to be of particular importance: providing several useful information on the general quality, freshness, maturity, storability, taste and/or on the optimization of selected technological processes ${ }^{[2]}$. Therefore, it is important and necessary for food producers and researchers to develop the fast, simply, reliably and accurately simultaneous determination of organic acids and monosaccharides.

At present, Gas chromatography (GC) and Highperformance liquid chromatography (HPLC) are dominant methods in the simultaneous determination of organic acid and sugars in food material ${ }^{[2]}$. Compared with the GC methods, simultaneous analysis of sugars and organic acids by HPLC could realized at low column temperature without sample derivatization and complicated gradient processes and give speed, reliability and sensitivity results without expensive detector (Mass spectra).Most of HPLC methods developed to analyze sugars and acids simultaneously utilized ion-exchange columns ${ }^{[3-6]}$. The 
typical Ion-exchange HPLC method for the investigation of organic acid and free sugars used an Aminex HPX-87H ion-exchange column $(300 \times 7.8 \mathrm{~mm})$ fitted with a cation $\mathrm{H}^{+}$microguard cartridge as stationary phase with acidified water (mostly $0.009 \mathrm{~mol} / \mathrm{L}_{2} \mathrm{H}_{2} \mathrm{SO}_{4}$ ) as mobile phase ${ }^{[7,8]}$.Unfortunately, many ion-exchange methods use dilute sulphuric acid as the mobile phase, high operating temperatures at about $60{ }^{\circ} \mathrm{C}$, expensive ion-exchange columns and have problems of co-elution of some of the organic acids and overlapping peaks ${ }^{[9]}$. Although reversed -phase high performance liquid chromatography (RPHPLC) methods determining sugars and acids simultaneously are advantageous in some of these respects: use of cheap columns, easier manipulation of the analytical parameters to optimize the separation, and the analyses were carried out at low temperature, but they couldn't give a satisfactory results due to poor selectivity and resolution in analyzing sugars $[2,9]$. Thanks to the remarkable improvements of HPLC column caused by the development of technology, it is possible to measure simultaneously a variety of organic acids and monosaccharaides by RP-HPLC.

The aim of this work was to develop a HPLC method for simultaneous determination of the main organic acids (benzoic, malic, citric and quinic acid) and the common monosaccharaides (glucose and fructose) in fruits and juice. This method should achieve these goals by optimizing the composition of mobile phase, column temperature and flow rate: having a brief separation period of less than 20 min per sample, the linear calibration curves for standards over a wide concentration range, the average relative standard deviations of below $5 \%$.

\section{MATERIALS AND METHODS}

\section{A. Chemicals}

All the solutions used ultrapure water from a Milli-Q Integral/10 system (Millipore, Tokyo, Japan). D(-)-Quinic acid was purchased from Acros Corporation (Belgium, NJ, USA). Citric acid, Benzoic acid, L(-)-Malic acid, D(+)Malic acid, Glucose, Fructose and Phosphoric acid were purchased from Wako Pure Chemical Industries, Ltd (Osaka, Japan). Acetonitrile (ACN) for mobile phase of HPLC was purchased from Sigma-Aldrich Japan Corporation (Tokyo, Japan).

\section{B. Equipment and Operating Conditions}

The analysis was carried out on an HPLC system consisting of an autosampler (AS-2055 plus, JASCO, Tokyo, Japan), a 4 solvent low pressure gradient pump (PU-2089, JASCO, Tokyo, Japan), an UV detector (UV2075 Plus, JASCO, Tokyo, JAPAN) and a refractive index detector (RI) (RI-2031 Plus, JASCO, Tokyo, Japan) equipped with a CAPCELL PAK $\mathrm{NH}_{2}$ column of $250 \times 4.6$ $\mathrm{mm}$ and $5 \mu \mathrm{m}$ particle size (Shiseido Co., Ltd., Tokyo, Japan). In this study, to simultaneous analysis of organic acid and sugars, UV and RI detectors were connected in series; the UV detector set at $210 \mathrm{~nm}$ was used for quantification of organic acid, while the RI detector set at $35{ }^{\circ} \mathrm{C}$ was used for determination of monosaccharaides. The ranges of UV and RI detector were 0.32 and 0.5 respectively. Signals of UV and RI detectors were analyzed by Chromato-pro software (Lab Company Co. Ltd., Tokyo, Japan).

To analyze the effect of operational factor on the performance of determination of sugars and acids and select the optimal operational parameter, One-factor experimental design was employed.

According to previous study, the mobile phase was the ACN solution. The ratio of ACN and water played a key role on the retention behaves of sugar and organic acid. The ratio of $\mathrm{ACN}$ and water was changed from $60 \%$ to $90 \%$ ACN concentration. Other factors were fixed as follows: the $\mathrm{pH}$ of mobile phase of 2.20 adjusted by $\mathrm{H}_{3} \mathrm{PO}_{4}$, the flow rate of $1.0 \mathrm{~mL} / \mathrm{min}$, the column temperature of 30 ${ }^{\circ} \mathrm{C}$, the injection volume of $10 \mu \mathrm{L}$. The composition of injection was shown in TABLE I.

TABLE I. THE COMPOSITION OF MODEL SOLUTION

\begin{tabular}{|c|c|}
\hline & Concentration (mM) \\
\hline Fructose & 5.0 \\
\hline Glucose & 5.0 \\
\hline Benzoic acid & 0.1 \\
\hline D(+)-Malic acid & 2.1 \\
\hline L(-)-Malic acid & 2.1 \\
\hline Citric acid & 4.8 \\
\hline Quinic acid & 5.4 \\
\hline
\end{tabular}

To avoid the ionization of acid, the $\mathrm{pH}$ of mobile phase should be lower than the $\mathrm{pK}_{\mathrm{a}}$ of the acids analyzed in this study. Too lower $\mathrm{pH}$ was detrimental to the column. So it is necessary for analyzing sugar and acid to select an appropriate $\mathrm{pH}$. The $\mathrm{pH}$ was variable from 2.00 to 2.60 , and other fixed factors included $75 \% \mathrm{ACN}$ as mobile phase, $1.0 \mathrm{~mL} / \mathrm{min}$ flow rate, $10 \mu \mathrm{L}$ injection volume and $30{ }^{\circ} \mathrm{C}$ column temperature.

To be clarified the effect of column temperature and optimize this parameter, temperature varied between 30 and $40{ }^{\circ} \mathrm{C}$, the fixed factors were listed as follows: $75 \%$ $\mathrm{ACN}(\mathrm{pH} 2.25), 1.0 \mathrm{~mL} / \mathrm{min}$ flow rate and $10 \mu \mathrm{L}$ injection volume.

To find the balance point among experiment cost, analysis time and separation performance, various flow rates were tested at $0.5-1.5 \mathrm{~mL} / \mathrm{min}$, other fixed conditions were shown in the following list: 75\% $\mathrm{ACN}(\mathrm{pH} 2.25), 35$ ${ }^{\circ} \mathrm{C}, 10 \mu \mathrm{L}$ injection volume.

\section{Validation Parameters and Statistical Treatment}

To evaluate this method, validation parameters consisting of regression equation, the coefficients of determination $\left(\mathrm{R}^{2}\right)$, relative standard deviation values (R. S. $\mathrm{D})$, limits of detection, linearity range and precision, accurate were analyzed ${ }^{[10]}$. Regression lines were expressed as

$$
\mathrm{y}=\mathrm{a}+\mathrm{bx}
$$

Where $\mathrm{x}$ was concentration $(\mathrm{mM})$, y represented the response area.

Six concentration points in triplicated were used to prepare the calibration curves. The concentrations of each compound were prepared from stock solutions by dissolving the proper quantity in $5 \mathrm{~mL}$ of $75 \% \mathrm{ACN}(\mathrm{pH}$ 
2.25). The peaks were identified by their retention times, comparing the UV or RI detector signal and spiking with standards. The linearity range was evaluated by plotting the peak area corresponding to each analyst, as a function of the concentration introduced. Precision involved interday repeatability which was estimated by calculating the R.S.D. values for the responses and retention times of the model solution in five successive injections during 3 consecutive days and intra-day repeatability which was evaluated by calculating the R. S. D. values for retention times and responses of the model solution in five successive injections. Accurate was calculated from the recovery rate at three levels for each compound, each sample was measured three times.

\section{Data Analysis}

The significant difference was set at 0.05 , and the data were analyzed by the software IBM SPSS Statistics 19.0 (IBM, Armonk, New York, USA).

\section{RESULTS AND DISCUSSION}

A. Effect of Composition and $\mathrm{pH}$ of Mobile Phase on the Separating Performance

As the time elapsed, Benzoic acid, Malic acid, Citric acid, Quinic acid, Fructose and Glucose successively eluted (Fig.1). The reason that the least polar compounds eluted first and the most polar compounds eluted last was that the CAPCELL PAK $\mathrm{NH}_{2}$ belonged to the normal phase and weak anion exchange column. Although this column couldn't separate the D(+)-Malic acid and L(-)Malic acid, it had some significant advantages, including high resolutions between adjacent peaks, symmetrical peaks, stable baseline and short elution time. According to these results, this column was suitable for analyzing sugars and acids simultaneously.

The retention time $\left(R_{t}\right)$ and peak area of organic acids and monosaccharaides at different ratios of $\mathrm{ACN}$ to water (ACN\%) are shown in Table II. The ACN\% had a significant influence on quantification of organic acids and sugars by HPLC. When the ACN\% was $60 \%$, a coelution of sugar and acids was observed in the signal of RI detection because too high polar mobile phase would decrease the difference in migration rates of sugars and acids. While the ACN was $90 \%$, Fructose and Glucose peaks disappeared in the signal of RI detection because sugars were more strongly retained in the weak polar mobile phase (Fig .2). The $70-80 \%$ ACN was feasible to determinate the sugars and acids on the same condition.

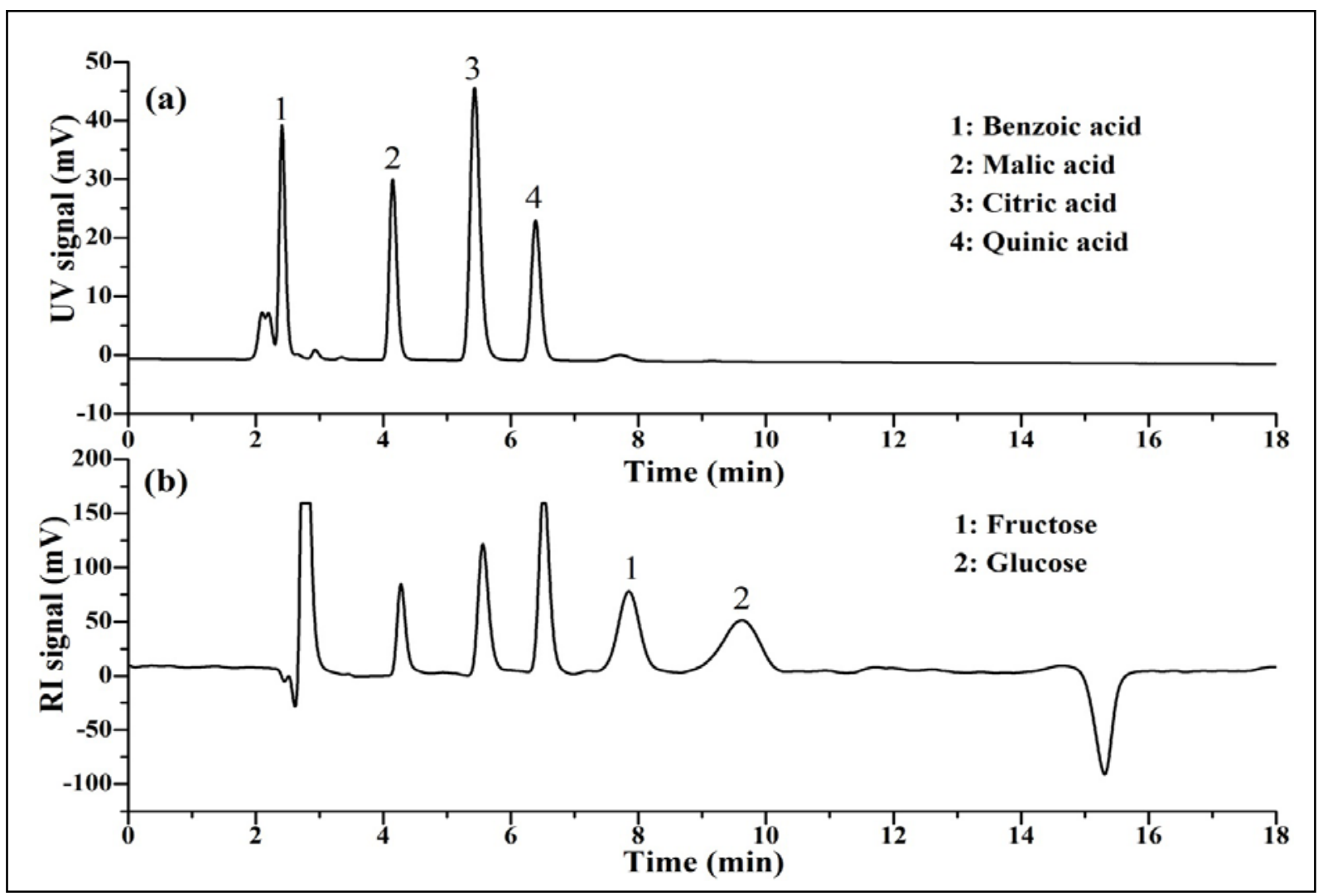

Figure 1. The elution profile of standard mixture in HPLC chromatograms

(a) The UV signal, (b) The RI signal 


\begin{tabular}{|c|c|c|c|c|c|c|c|}
\hline & ACN (\%) & Benzoic acid & Malic acid & Citric acid & Quinic acid & Fructose $^{[\mathrm{a}]}$ & Glucose $^{[a]}$ \\
\hline \multirow{5}{*}{$\begin{array}{l}\mathrm{R}_{\mathrm{t}}^{[\mathrm{b}]} \\
(\mathrm{min})\end{array}$} & $60 \%$ & 2.44 & 3.66 & 4.24 & 4.71 & n.d. & n.d. \\
\hline & $70 \%$ & 2.39 & $3.83^{\mathrm{c}}$ & $4.80^{\mathrm{c}}$ & $5.29^{\mathrm{c}}$ & $6.24^{\mathrm{c}}$ & $7.29^{\mathrm{c}}$ \\
\hline & $75 \%$ & 2.40 & $4.22^{\mathrm{b}}$ & $5.60^{\mathrm{b}}$ & $6.63^{\mathrm{b}}$ & $8.20^{\mathrm{b}}$ & $10.05^{\mathrm{b}}$ \\
\hline & $80 \%$ & 2.43 & $4.31^{\mathrm{a}}$ & $5.73^{\mathrm{a}}$ & $8.45 \pm 0.01^{\mathrm{a}}$ & $11.81 \pm 0.03^{\mathrm{a}}$ & $15.20 \pm 0.03^{\mathrm{a}}$ \\
\hline & $90 \%$ & 2.50 & $4.92 \pm 0.01$ & $6.55 \pm 0.02$ & $17.34 \pm 0.38$ & n.d & n.d \\
\hline \multirow{5}{*}{$\begin{array}{c}\text { Peak } \\
\text { Area } \\
{[\mathrm{b}]}\end{array}$} & $60 \%$ & $\begin{array}{l}254876.7 \\
\pm 4188.75\end{array}$ & $\begin{array}{c}258063.6 \\
\pm 7950.50\end{array}$ & $\begin{array}{l}270951.19 \\
\pm 4321.76\end{array}$ & $\begin{array}{l}511946.38 \\
\pm 8487.00\end{array}$ & n.d & n.d \\
\hline & $70 \%$ & $\begin{array}{r}271204.1 \\
\pm 8774.13\end{array}$ & $\begin{array}{l}269486.15 \\
\pm 7508.17^{\mathrm{a}}\end{array}$ & $\begin{array}{c}527389.39 \\
\pm 25126.86^{\mathrm{a}}\end{array}$ & $\begin{array}{c}260619.89 \\
\pm 15153.13^{\mathrm{a}}\end{array}$ & $\begin{array}{l}1622352.72 \\
\pm 103578.2^{\mathrm{b}}\end{array}$ & $\begin{array}{r}1704632.27 \\
\pm 77315.83^{\mathrm{b}}\end{array}$ \\
\hline & $75 \%$ & $\begin{array}{c}260596.1 \pm 1552 \\
31\end{array}$ & $\begin{array}{r}248339.40 \\
\pm 1291.31^{\mathrm{b}}\end{array}$ & $\begin{array}{r}494932.24 \\
\pm 1493.84^{\mathrm{b}}\end{array}$ & $\begin{array}{c}244367.64 \\
\pm 4925.24^{\text {ab }}\end{array}$ & $\begin{array}{r}1292155.84 \\
\pm 44021.26^{\mathrm{c}}\end{array}$ & $\begin{array}{r}1407157.80 \\
\pm 15365.94^{\mathrm{b}}\end{array}$ \\
\hline & $80 \%$ & $\begin{array}{c}264616.1 \\
\pm 66.73\end{array}$ & $\begin{array}{l}246774.97 \\
\pm 508.47^{\mathrm{b}}\end{array}$ & $\begin{array}{l}494239.52 \\
\pm 862.27^{\mathrm{b}}\end{array}$ & $\begin{array}{l}235429.17 \\
\pm 663.40^{\mathrm{b}}\end{array}$ & $\begin{array}{r}1959416.32 \\
\pm 251869.2^{\mathrm{a}}\end{array}$ & $\begin{array}{r}2083050.89 \\
\pm 246688.22^{\mathrm{a}} \\
\end{array}$ \\
\hline & $90 \%$ & $\begin{array}{l}280701.0 \\
\pm 634.37\end{array}$ & $\begin{array}{l}239668.7 \\
\pm 967.41\end{array}$ & $\begin{array}{c}484621.63 \\
\pm 406.29\end{array}$ & $\begin{array}{c}198362.15 \\
\pm 657.72\end{array}$ & n.d & n.d \\
\hline
\end{tabular}

[b] Same lowercases within data from $70 \% \mathrm{ACN}$ to $80 \% \mathrm{ACN}$ in each column are not significantly different from each other $(p<0.05)$.
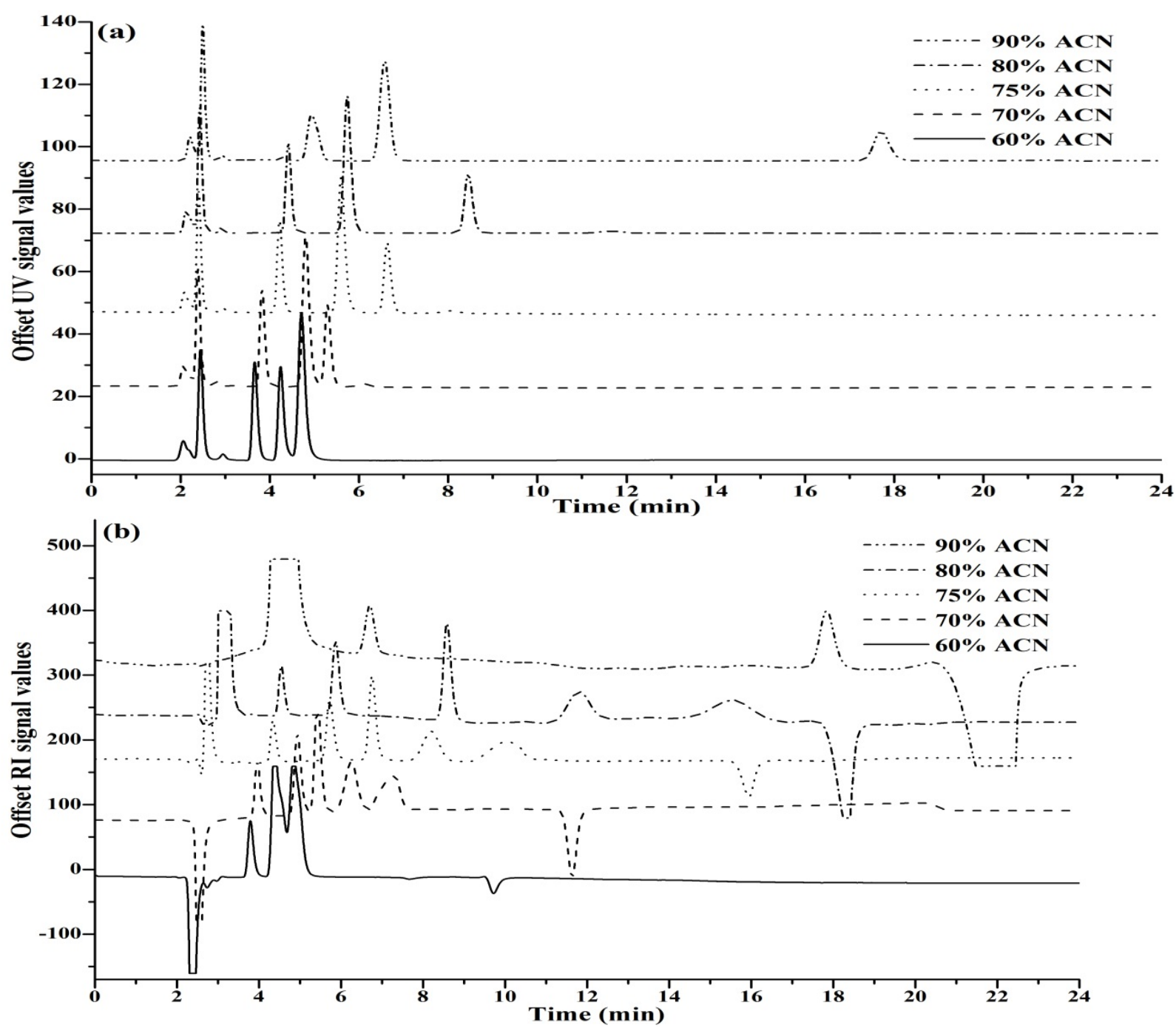

Figure 2. HPLC chromatograms of model solution at various ACN content (a) The UV signal, (b) The RI signal

To optimize the ACN\%, comparisons between retention time and peak area of different $\mathrm{ACN} \%$ groups were tested by one-way anova and Duncan test. One conclusion that could be drawn from the data in Table II 
was that $70 \% \mathrm{ACN}$ shorten elution time and generate larger peak areas of acids, but produce higher standard deviations that had a detrimental effect on reliability of quantification of organic acids and sugars by HPLC; conversely, higher ACN\% would reduce the peak areas of acids and increase the peak areas of sugar significantly, but it took a longer time to finish one analysis and increased the cost of experiment. All things considered, $75 \% \mathrm{ACN}$ was the more suitable ratio of $\mathrm{ACN}$ to water for quantification of acids and sugars.

The effects of $\mathrm{pH}$ of mobile phase on the elution profile were shown in Fig .3. At $\mathrm{pH}$ 2.6, retention times of Malic, Citric and Quinic acids were higher than samples analyzed at other $\mathrm{pH}$, a co-elution of Quinic acid and
Fructose was observed in RI signal. By decreasing to $\mathrm{pH}$ 2.4 the resolution of Citric acid with respect to Quinic acid was incomplete. So it was not suitable for simultaneous quantification of sugars and acids at $\mathrm{pH} 2.4$ and $\mathrm{pH} 2.6$. Elution curves of samples analyzed at $\mathrm{pH} 2.30,2.25,2.20$ were similar. At $\mathrm{pH} 2.00$, retention times of all components except Benzoic acid in this research continued to shorten. It was not feasible to analyze acids and sugars simultaneously at $\mathrm{pH} 2.00$ because $\mathrm{pH} 2.00$ was close to the lower limit of operational $\mathrm{pH}$ of this column.

From the data in the Table III, it could be reasonably inferred that the optimum $\mathrm{pH}$ is 2.25 . At this condition, this method had high sensitivity and reliability by means of higher peak area and lower standard deviation.

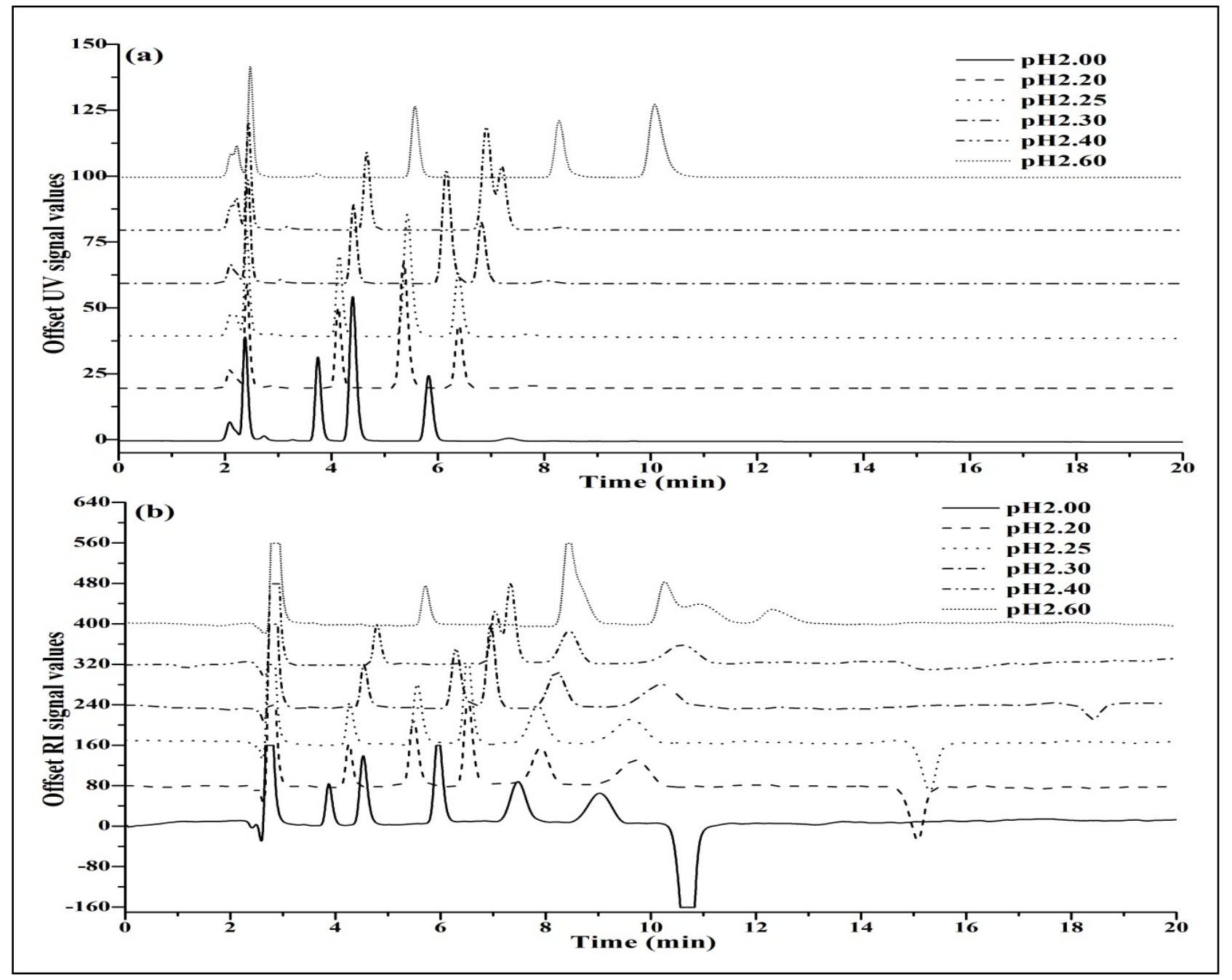

Figure 3. HPLC chromatograms of model solution at different $\mathrm{pH}$ of mobile phase

(a) The UV signal, (b) The RI signal

TABLE III. PEAK AREA OF ORGANIC ACIDS AND MONOSACCHARAIDES AT THE VARIOUS pH OF MOBILE PHASE

\begin{tabular}{|c|c|c|c|c|c|c|}
\hline $\begin{array}{c}\text { pH of } \\
\text { mobile phase }\end{array}$ & $\begin{array}{c}\text { Benzoic } \\
\text { acid }^{[a]}\end{array}$ & $\begin{array}{l}\text { Malic } \\
\text { acid }^{[a]}\end{array}$ & $\begin{array}{l}\text { Citric } \\
\text { acid }^{\text {[a] }}\end{array}$ & $\begin{array}{l}\text { Quinic } \\
\text { acid }^{[a]}\end{array}$ & Fructose $^{[a]}$ & Glucose $^{[a]}$ \\
\hline $\mathrm{pH} 2.20$ & $\begin{array}{c}259332.18 \pm \\
916.38^{\mathrm{b}} \\
\end{array}$ & $\begin{array}{c}246474.78 \pm \\
383.68^{\mathrm{b}} \\
\end{array}$ & $\begin{array}{c}502080.45 \pm \\
908.58^{\mathrm{c}} \\
\end{array}$ & $\begin{array}{c}240685.57 \pm \\
744.90^{\mathrm{b}}\end{array}$ & $\begin{array}{c}1655963.02 \pm \\
33394.85^{\mathrm{b}}\end{array}$ & $\begin{array}{c}1990335.52 \pm \\
9716.89^{\mathrm{b}} \\
\end{array}$ \\
\hline $\mathrm{pH} 2.25$ & $\begin{array}{c}263416.49 \pm \\
421.53^{\mathrm{a}}\end{array}$ & $\begin{array}{c}250573.65 \pm \\
266.76^{\mathrm{a}}\end{array}$ & $\begin{array}{c}503879.38 \pm \\
651.24^{\mathrm{b}}\end{array}$ & $\begin{array}{c}243745.40 \pm \\
169.69^{\mathrm{a}}\end{array}$ & $\begin{array}{c}1895943.83 \pm \\
14688.15^{\mathrm{a}}\end{array}$ & $\begin{array}{c}1976558.50 \pm \\
18089.82^{\mathrm{b}}\end{array}$ \\
\hline $\mathrm{pH} 2.30$ & $\begin{array}{c}260077.06 \pm \\
1796.44^{\mathrm{b}}\end{array}$ & $\begin{array}{c}248058.15 \pm \\
1866.35^{\mathrm{b}}\end{array}$ & $\begin{array}{c}505968.67 \pm \\
192.87^{\mathrm{a}}\end{array}$ & $\begin{array}{c}241243.81 \pm \\
1357.54^{\mathrm{b}}\end{array}$ & $\begin{array}{c}1820208.39 \pm \\
104779.15^{\mathrm{a}}\end{array}$ & $\begin{array}{c}2143551.99 \pm \\
105662.48^{\mathrm{a}}\end{array}$ \\
\hline
\end{tabular}




\section{B. Effect of Column Temperature on Separating Performance}

It was clear that as the temperature raised, the peak areas and peak heights of Citric acid, Malic acid, Quinic acid, Fructose and Glucose increased except Benzoic acid, the retention times of Citric acid, Malic acid, Quinic acid, Fructose and Glucose decreased except Benzoic acid, moreover the symmetry of peak of Glucose improved due to reducing the tailing (Fig .4). The reason why variation of temperature generated these phenomena was that the polarity of mobile phase would strengthen by increasing temperature, which would lead to reduce the retention of component in the column. High migration rate reduced the band broadening effectively so that the peaks became sharper. It could be seen that the peak of Benzoic acid was near the void volume peak. It was inferred that Benzoic acid was nearly unretained by the stationary phase in this system, so the variation of polarity of mobile phase caused by changing temperature had little effect on the elution behave of Benzoic acid.

Although higher temperature is advantage to shorten retention time, intensify the signal strength, high temperature would reduce the life of HPLC column and aggravate the variation of baseline. Therefore, $35{ }^{\circ} \mathrm{C}$ was the optimum temperature to analyze acid and sugar simultaneously by HPLC.

\section{Effect of Flow Rate on the Separating Performance}

The Fig .5 shows clearly that the elution curves of samples at different flow rates are similar, the retention times decrease substantially by increasing the flow rate from $0.5 \mathrm{~mL} / \mathrm{min}$ to $1.5 \mathrm{~mL} / \mathrm{min}$. Through analyzing the peak areas of samples by the one-way anova and Duncan test, it was concluded that the flow rate was the significant factor of peak area of all components in this research. High peak area could be responded at Low flow rate that meant high sensitivity at low flow rate (Table IV). However, in order to complete one analysis within $20 \mathrm{~min}$, the flow rate of $1.0 \mathrm{~mL} / \mathrm{min}$ was the final selection. At this condition, it could supply a considerably high sensitivity and reliability.

Therefore, the optimal conditions for rapidly analyzing organic acids and sugars simultaneously were: $75 \% \mathrm{ACN}$, $\mathrm{pH}$ of 2.25 , flow rate of $1.0 \mathrm{~mL} / \mathrm{min}$, the column temperature of $35{ }^{\circ} \mathrm{C}$. Under these conditions, this HPLC procedure had the advantages of: (a) having a brief separation period of 20 min per sample; (b) no overlapping peaks; (c) high response areas and symmetric peaks.

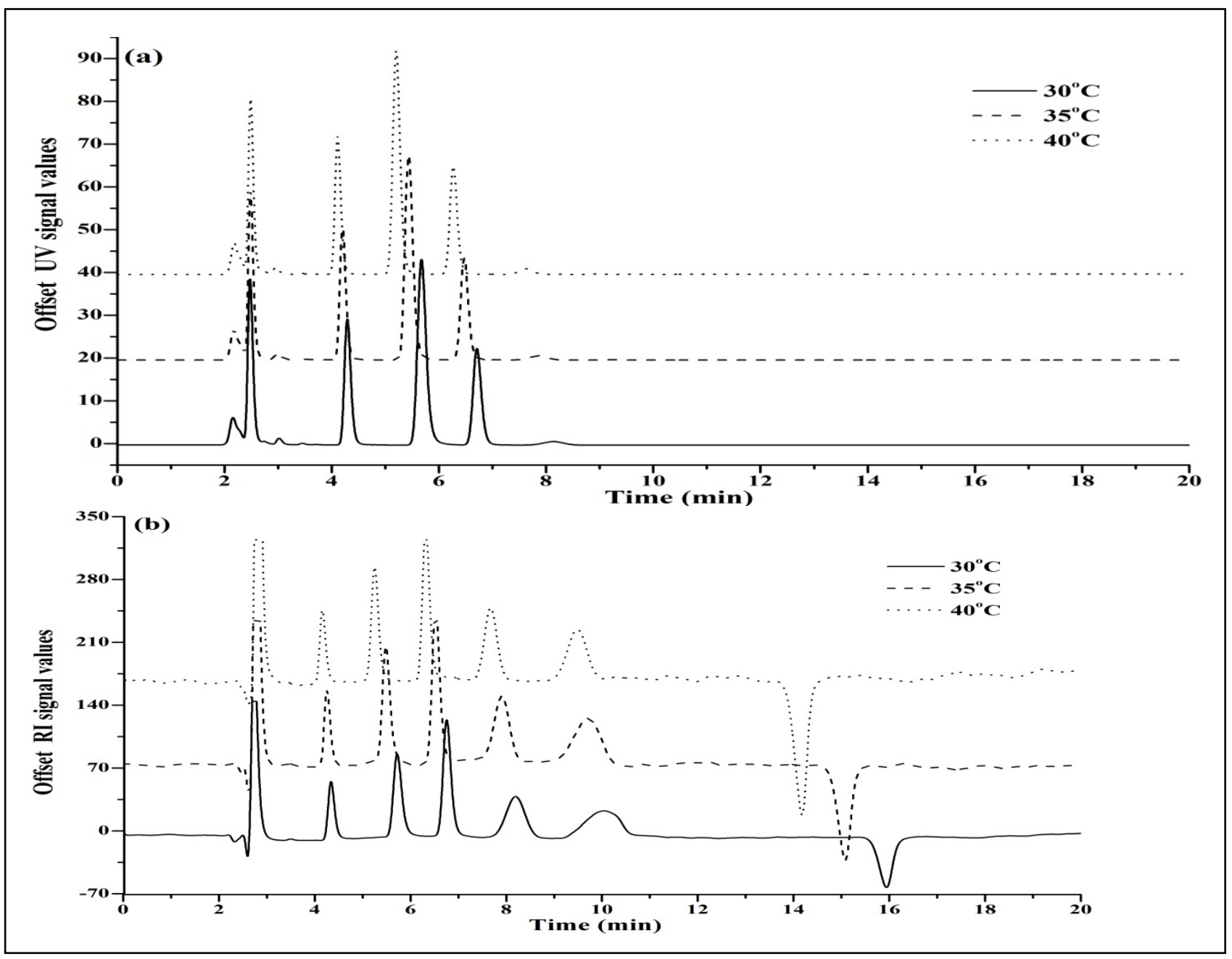

Figure 4. HPLC chromatograms of standard mixture at different temperature

(a) The UV signal, (b) The RI signal 


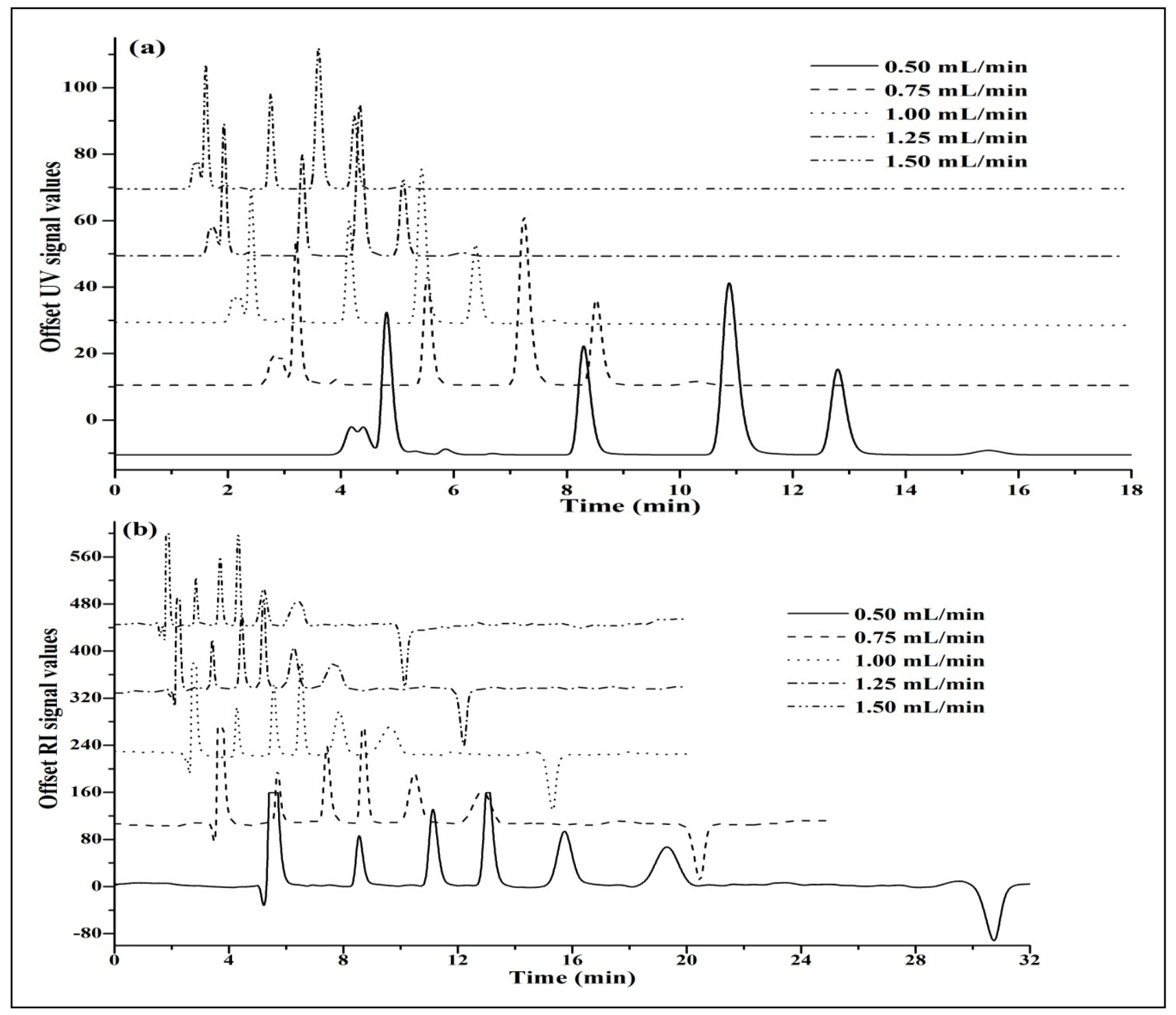

Figure 5. HPLC chromatograms of standard mixture at different flow rate (a) The UV signal, (b) The RI signal

TABLE IV. PEAK AREA OF ORGANIC ACIDS AND MONOSACCHARAIDES AT THE VARIOUS FLOW RATE

\begin{tabular}{|c|c|c|c|c|c|c|}
\hline $\begin{array}{l}\text { Flow rate } \\
(\mathrm{mL} / \mathrm{min})\end{array}$ & $\begin{array}{c}\text { Benzoic } \\
\text { acid }^{\text {a] }}\end{array}$ & $\begin{array}{l}\text { Malic } \\
\text { acid }^{\text {[a] }}\end{array}$ & $\begin{array}{l}\text { Citric } \\
\text { acid }^{\text {[a] }}\end{array}$ & $\begin{array}{l}\text { Quinic } \\
\text { acid }^{[a]}\end{array}$ & Fructose $^{[\mathrm{a}]}$ & Glucose $^{[\mathrm{a}]}$ \\
\hline 0.50 & $\begin{array}{c}517356.80 \\
\pm 496.33^{\mathrm{a}} \\
\end{array}$ & $\begin{array}{c}490027.30 \\
\pm 153.30^{\mathrm{a}} \\
\end{array}$ & $\begin{array}{c}992753.90 \\
\pm 729.30^{\mathrm{a}}\end{array}$ & $\begin{array}{c}471530.63 \\
\pm 9.67^{\mathrm{a}}\end{array}$ & $\begin{array}{c}4319345.50 \\
\pm 250727.50^{\mathrm{a}}\end{array}$ & $\begin{array}{l}3786495.60 \\
\pm 54198.00^{\mathrm{a}}\end{array}$ \\
\hline 0.75 & $\begin{array}{l}350250.03 \\
\pm 5076.88^{\mathrm{b}} \\
\end{array}$ & $\begin{array}{l}333800.93 \\
\pm 4839.16^{\mathrm{b}} \\
\end{array}$ & $\begin{array}{r}678461.65 \\
\pm 10959.94^{\mathrm{b}} \\
\end{array}$ & $\begin{array}{l}324859.12 \\
\pm 4893.79^{\mathrm{b}} \\
\end{array}$ & $\begin{array}{c}2276347.86 \\
\pm 171960.84^{\mathrm{b}} \\
\end{array}$ & $\begin{array}{r}2347553.18 \\
\pm 51292.04^{\mathrm{b}} \\
\end{array}$ \\
\hline 1.00 & $\begin{array}{c}263416.49 \\
\pm 421.53^{\mathrm{c}}\end{array}$ & $\begin{array}{c}250573.65 \\
\pm 266.76^{c}\end{array}$ & $\begin{array}{c}503879.38 \\
\pm 651.24^{\mathrm{c}}\end{array}$ & $\begin{array}{c}243745.40 \\
\pm 169.69^{\mathrm{c}}\end{array}$ & $\begin{array}{l}1895943.83 \\
\pm 14688.15^{\mathrm{c}}\end{array}$ & $\begin{array}{l}1976558.50 \\
\pm 18089.82^{c}\end{array}$ \\
\hline 1.25 & $\begin{array}{l}215998.51 \\
\pm 2475.31^{\mathrm{d}}\end{array}$ & $\begin{array}{l}204778.50 \\
\pm 2073.40^{d}\end{array}$ & $\begin{array}{l}409073.10 \\
\pm 3899.00^{\mathrm{d}}\end{array}$ & $\begin{array}{l}199315.80 \\
\pm 1681.90^{\mathrm{d}}\end{array}$ & $\begin{array}{l}1443818.39 \\
\pm 67102.74^{\mathrm{d}}\end{array}$ & $\begin{array}{l}1482891.39 \\
\pm 18819.81^{\mathrm{d}}\end{array}$ \\
\hline 1.50 & $\begin{array}{c}178145.44 \\
\pm 73.16^{\mathrm{e}}\end{array}$ & $\begin{array}{c}168712.43 \\
\pm 260.22^{\mathrm{e}}\end{array}$ & $\begin{array}{l}340361.00 \\
\pm 4250.00^{\mathrm{e}}\end{array}$ & $\begin{array}{c}164053.20 \\
\pm 161.30^{\mathrm{e}}\end{array}$ & $\begin{array}{l}1184944.88 \\
\pm 41026.82^{\mathrm{e}}\end{array}$ & $\begin{array}{l}1249932.58 \\
\pm 48602.83^{\mathrm{e}}\end{array}$ \\
\hline
\end{tabular}

[a] a, b, c, d, e means values with different superscripts with each column differed significantly $(p<0.05)$

\section{Determination of Validation Parameters}

The calibration curves of Benzoic, Malic, Citric and Quinic acid, Fructose, Glucose were established by six concentration points in triplicated at the optimal conditions. The calibration curves were shown in Table $\mathrm{V}$. The coefficients of determination $\left(\mathrm{R}^{2}\right)$ obtained were excellent with values better than 0.9995, except for Glucose (0.9993). To verify the linearity of this method, the response factor (f) were calculated by dividing the peak area obtained in the chromatogram and the corresponding concentration. The R. S. D. values of $\mathrm{f}$ were below $5 \%$ considered adequate to verity the linearity of the regression lines for analytical methods. According to the range, this 
method could provide a wide analytical range. Benzoic acid consists of a benzene group which has a strong ultraviolet absorption, so the detection range of Benzoic acid measured by UV detector was lower than other organic acids.

Table VI shows the results obtained when studying the precision of this method. The R. S. D. values obtained when analyzing the intra-day repeatability were lower than those obtained inter-day except for R. S. D. values for Rt of fructose and glucose. Compared with the R. S. D. values for response, the R. S. D. values for retention time were lower. Due to the deviation $<5 \%$, this method could give a stable results. In order to evaluate the accuracy of this method, the recoveries were studied by comparing the known concentration of organic acids and monosaccharides with the concentrations quantified using the calibration curves. Recoveries ranged from 93.82 to $107.42 \%$ for all the components at different levels, and most of recoveries were closed to $100 \%$, that meant this method had a satisfactory accuracy (Table VII).

TABLE V. REGRESSION EQUATIONS AND LINEARITY OF THE CALIBRATION CURVES

\begin{tabular}{|c|c|c|c|c|}
\hline Component & Range (mM) & Regression equation & R $^{\mathbf{2}}$ & R. S. D. of f (\%) $^{[\mathbf{a}]}$ \\
\hline Benzoic acid & $0.017-3.6$ & $\mathrm{Y}=2369948.9368 \mathrm{x}+11695.0094$ & 0.9999 & 2.88 \\
\hline Malic acid & $0.30-175$ & $\mathrm{Y}=56320.4122 \mathrm{x}-17417.6876$ & 1.0000 & 3.41 \\
\hline Citric acid & $0.09-200$ & $\mathrm{Y}=101170.8407 \mathrm{x}-1903.3601$ & 0.9999 & 3.23 \\
\hline Quinic acid & $0.30-300$ & $\mathrm{Y}=40337.8878 \mathrm{x}+55900.8968$ & 0.9997 & 3.99 \\
\hline Fructose & $0.2-14$ & $\mathrm{Y}=329161.1642 \mathrm{x}+24247.7498$ & 0.9996 & 3.34 \\
\hline Glucose & $0.3-16$ & $\mathrm{Y}=340970.5622 \mathrm{x}+75340.0745$ & 0.9993 & 3.95 \\
\hline
\end{tabular}

[a] R. S. D. of $\mathrm{f}(\%)$ means the percentage of the relative standard deviation of the response factor

TABLE VI. RESULTS OF THE ANALYSIS OF INTRA- DAY AND INTER- DAY REPEATABILITY

\begin{tabular}{|c|c|c|c|c|c|}
\hline Component & $\begin{array}{c}\text { Concentration } \\
(\mathbf{m M})\end{array}$ & $\begin{array}{c}\text { R. S. D. for } R_{t} \\
\text { (intra-day) (\%) }\end{array}$ & $\begin{array}{l}\text { R. S. D. for } \mathbf{R}_{t} \\
\text { (inter-day) (\%) }\end{array}$ & $\begin{array}{c}\text { R. S. D. for R } \\
\text { (intra-day) (\%) }\end{array}$ & $\begin{array}{c}\text { R. S. D. for R } \\
\text { (inter-day) (\%) }\end{array}$ \\
\hline Benzoic acid & 0.1 & 0 & 0.1907 & 0.1304 & 0.3699 \\
\hline Malic acid & 4.2 & 0.1060 & 0.1407 & 0.1068 & 0.1727 \\
\hline Citric acid & 4.8 & 0.0799 & 0.0817 & 0.0958 & 0.3763 \\
\hline Quinic acid & 5.4 & 0.0675 & 0.0913 & 0.2072 & 0.9153 \\
\hline Fructose & 5.0 & 0.2381 & 0.2300 & 1.213 & 2.271 \\
\hline Glucose & 5.0 & 0.3206 & 0.3089 & 1.257 & 2.235 \\
\hline
\end{tabular}

TABLE VII. RESULTS OF THE RECOVERY CALCULATED AT THREE DIFFERENT LEVELS

\begin{tabular}{|c|c|c|}
\hline Component & Concentration (mM) & Recovery (\%) \\
\hline \multirow{3}{*}{ Benzoic acid } & 0.075 & $98.30 \pm 1.96$ \\
\hline & 0.15 & $107.42 \pm 1.08$ \\
\hline & 0.30 & $104.28 \pm 0.41$ \\
\hline \multirow{3}{*}{ Malic acid } & 2.40 & $100.04 \pm 0.98$ \\
\hline & 3.60 & $100.05 \pm 1.24$ \\
\hline & 4.80 & $98.28 \pm 0.49$ \\
\hline \multirow{3}{*}{ Citric acid } & 0.60 & $98.43 \pm 1.00$ \\
\hline & 1.20 & $98.66 \pm 1.02$ \\
\hline & 2.40 & $99.57 \pm 0.23$ \\
\hline \multirow{3}{*}{ Quinic acid } & 0.60 & $96.50 \pm 0.88$ \\
\hline & 0.90 & $96.59 \pm 0.44$ \\
\hline & 1.80 & $98.33 \pm 0.95$ \\
\hline \multirow{3}{*}{ Fructose } & 1.40 & $93.26 \pm 1.96$ \\
\hline & 2.00 & $95.51 \pm 3.76$ \\
\hline & 3.20 & $97.96 \pm 6.49$ \\
\hline \multirow{3}{*}{ Glucose } & 6.00 & $93.82 \pm 2.75$ \\
\hline & 8.00 & $99.49 \pm 4.35$ \\
\hline & 10.00 & $103.07 \pm 3.04$ \\
\hline
\end{tabular}

\section{CONCLUSIONS}

A proposed HPLC allows the simultaneous determination of common organic acids and monosaccharides in food industry. By means of analyzing the effects of operational factors and optimizing them, this method could achieve adequate separation within $18 \mathrm{~min}$. According to the validation study, the linearity, precision and accuracy of this method are satisfactory. Moreover, the procedure of this method is very sample, involves little sample preparation which just consists of dilution and filtration before injection, and the cost of this method is relative low compared with ion-exchange HPLC method. Therefore, this method appears to be an alternative routine analysis to other analytical HPLC methods for determination of the main organic acids and common monosaccharides in the beverage industry. Furthermore, this method may be easily extent to determinate other organic acids and monosaccharides. 


\section{ACKNOWLEDGMENT}

We would like to thank UNU-Kirin Fellowship 2013-2014 for the financial support to our research.

\section{REFERENCES}

[1] H. D. Belitz, W. Grosch, P. Schieberle, Food chemistry, 4th ed., Berlin: Springer -Verlag, 2009, pp. 429-466.

[2] I. Molnár-Perl, "Simultaneous quantitation of acids and sugars by chromatography: gas or high-performance liquid chromatography? " J CHROMATOGR A, vol. 845, pp. 181-195, June 1999.

[3] Y. Beaulieu, D. St-Gelais, C. J. Randall, G. Gaudreau, "Simultaneous HPLC determination of Organic Acids, Sugars and Alcohols," Can Inst Food Sci Technol J, vol. 24, pp. 87-94, February 1991.

[4] H. G. Robert, H. S. Huang, L. T. Chuang, et al, "Changes in sugars, organic acids and amino acids in medlar (Mespilus germanica L.) during fruit development and maturation," FOOD CHEM, vol. 83, pp. 363-369, November 2003.

[5] W. J. Mullin, D. B. Emmons, "Determination of organic acids and sugars in cheese, milk and whey by high performance liquid chromatography," FOOD RES INT, vol. 30, pp. 147-151, March 1997.

[6] J. F. R. Lues, W. C. Botha, E. J. Smit, "Ion-exchange HPLC analysis of a broad spectrum of organic acids from matured Cheddar cheese and assessment of extraction methods," FOOD RES INT, vol. 31, pp. 441-447, August 1998.

[7] A. M. Lombardi, A. E. Bevilacqua, A. N. Califano, "Variation in organic acids content during ripening of Reggianito cheese in air-tight sealed bags," FOOD CHEM, vol. 51, pp. 221-226, June 1994.

[8] D. González de Llano, A. Rodriguez, P. Cuesta, "Effect of lactic starter cultures on the organic acid composition of milk and cheese during ripening-analysis by HPLC," J APPL BACTERIOL, vol. 80, pp. 570-576, May 1996.

[9] M. Tormo, J. M. Izco, "Alternative reversed-phase highperformance liquid chromatography method to analyse organic acids in dairy products," J CHROMATOGR A, vol. 1033, pp. 305-310, April 2004.

[10] R. Scherer, A. C. P. Rybkaa, C. A. Ballus, A. D. Meinhart, J. T. Filho, H. T. Godoy, "Validation of a HPLC method for simultaneous determination of main organic acids in fruits and juices," FOOD CHEM, vol. 135, pp. 150-154, November 2012. 